\title{
Autorenverzeichnis Band 5,1995
}

Arenz,D. 3149 Bailer, J. 4217 Becker, E.S. 4207 Berbalk, H. 15 Brenner, H.D. 2 68,2 96 Döring-Seipel, E. 3138 Ernst-Goergens, B. 4226 Essau, C.A. 4226 Goertz,Y. 281 Hahlweg, K. Suppl. 11 Hamm,A.O. 4200 Hand, I. 3134 Heimberg,D. 268 Hellhammer, D. Suppl. 116 Hirsbrunner, A. 268 Horn,R. 281 Jenull,B. 2 68,2 96 Kempkensteffen, J. 15 Keppeler,U. 296 Kirschbaum, C. Suppl. 116 Kupfer,B. 121 Laux,G. 281 Miretzky, A. 281 Möller, H.-J. 281 Mussgay, L. Suppl. 19

Nübling, R. 289 Ockenfels, M. Suppl. 116 Osen,B. 3134 Pelzer,E. 281 Petermann, F. 4226 Porter, L. Suppl. 116 Rist,F. 4217 Roder,V. 2 68,2 96 Rose, A. 3154

Rüddel, H. 2 89, Suppl. 11-V Schroer,B. 3161 Schüler,P. 3138 Schulte,D. 142 Schulz,H. 289 Seipel,K.H. 3138 Smyth, J. Suppl. 116 Staehle,HJ. 4217 Stone, A. Suppl. 116 Süss-Burghart, H. 135 Theilemann, S. 130 Ubben, B. 4232 Vaitl,D. 4200 Vossen,A. 3120 Weyerer,S. 121 Wittchen, H.-U. 3120 